\title{
High-energy phonon confinement in nanoscale metallic multilayers
}

\author{
B. Roldan Cuenya, ${ }^{1, *}$ W. Keune, ${ }^{1,2}$ R. Peters, ${ }^{2}$ E. Schuster, ${ }^{2}$ B. Sahoo, ${ }^{2}$ U. von Hörsten, ${ }^{2}$ W. Sturhahn, ${ }^{3}$ J. Zhao, ${ }^{3}$ \\ T. S. Toellner, ${ }^{3}$ E. E. Alp, ${ }^{3}$ and S. D. Bader ${ }^{4}$ \\ ${ }^{1}$ Department of Physics, University of Central Florida, Orlando, Florida 32816, USA \\ ${ }^{2}$ Fachbereich Physik, Universität Duisburg-Essen, D-47048 Duisburg, Germany \\ ${ }^{3}$ Advanced Photon Source, Argonne National Laboratory, Argonne, Illinois 60439, USA \\ ${ }^{4}$ Materials Science Division, Argonne National Laboratory, Argonne, Illinois 60439, USA
}

(Received 7 March 2008; published 8 April 2008)

\begin{abstract}
The Fe-projected vibrational density of states $g(E)$ in nanoscale ${ }^{57} \mathrm{Fe} / M$ multilayers, where $M=\mathrm{Cr}, \mathrm{Co}, \mathrm{Cu}$, $\mathrm{Pd}$, or Ag was measured by nuclear resonant inelastic x-ray scattering. With decreasing Fe thickness, the high-energy phonon peak of Fe near $36 \mathrm{meV}$ is suppressed for the "soft" metals $\mathrm{Ag}, \mathrm{Pd}$, and $\mathrm{Cu}$, but much less so for the "hard" metals Co and Cr. This effect is attributed to Fe phonon confinement and interface localization due to an energy mismatch between $g(E)$ of $M$ and of Fe.
\end{abstract}

DOI: $10.1103 /$ PhysRevB.77.165410

PACS number(s): 63.22.- m, 63.20.-e, 68.65.Ac

\section{INTRODUCTION}

The lattice dynamics of thin-film multilayers has attracted considerable experimental and theoretical interest. ${ }^{1}$ Novel phenomena such as zone-folded, confined, and localized interface vibrational modes, which have no analog in bulk materials, have been discovered. ${ }^{2-5}$ Phonon confinement appears when no propagating vibrational mode is allowed in one of the constituent layers, while phonon localization implies phonon modes with a limited number of atoms involved in the vibrations. Phonon confinement and localization are general phenomena in low dimensional materials ${ }^{5}$ and may lead to modifications of the vibrational density of states (VDOS), $g(E)$, and, consequently, to changes in the thermodynamic properties relative to bulk materials. For instance, confinement offers the possibility to tailor the thermal conductivity in order to achieve the low values required to improve the thermoelectric figure of merit in metal-based superlattices, ${ }^{6}$ to create band gaps in artificial structures known as phononic crystals, ${ }^{7}$ to contribute to the electronphonon mass enhancement in nanoscale multilayers, ${ }^{8}$ and to influence the functioning of future thermal logic gates. ${ }^{9}$ The fundamental question of how $g(E)$ in nanoscale multilayers is modified as compared to bulk materials is relatively unexplored and remains an experimental challenge to date. Raman spectroscopy has been used to study semiconducting superlattices ${ }^{1-4}$ and confined optical phonons in metallic $(\mathrm{Co} / \mathrm{Ru})$ multilayers. ${ }^{10}$ However, Raman scattering is sensitive to long wavelength phonons and cannot be used to determine $g(E)$. This applies also for Brillouin light scattering, which revealed localized phonon modes due to interfaceinduced modifications of elastic force constants in metallic multilayer structures. ${ }^{11-13}$ The classical method of inelastic neutron scattering remains challenging because of insufficient sensitivity. Recently, first-principles calculations ${ }^{14}$ for monolayer-scale $\mathrm{Fe}(001) / \mathrm{Au}(001)$ superlattices predicted drastic variations of $g(E)$ with $t_{\mathrm{Au}}$ and $t_{\mathrm{Fe}}$, where $t$ is the layer thickness.

In this work, we present an investigation of the $\mathrm{Fe}$ projected VDOS in nanoscale $\mathrm{Fe} / M$ multilayers by ${ }^{57} \mathrm{Fe}$ nuclear resonant inelastic x-ray scattering (NRIXS), where
$M=\mathrm{Cr}, \mathrm{Co}, \mathrm{Cu}, \mathrm{Pd}$, or $\mathrm{Ag}$. The confinement of phonons at the Brillouin zone boundary and interface localization are shown via an observation of a striking dependence of the phonon peak height $(\mathrm{PH})$ and position on the energy mismatch between the VDOS of the two materials near the maximum phonon energies and on the Fe layer thickness.

\section{EXPERIMENTS AND SAMPLE CHARACTERIZATION}

Polycrystalline $\left[{ }^{57} \mathrm{Fe}\left(t_{\mathrm{Fe}}\right) / M\left(t_{M}\right)\right]_{15}$ multilayers, with $t_{M}$ $=4 \mathrm{~nm}$ and $t_{\mathrm{Fe}}=1.5,2,4$, and $8 \mathrm{~nm}$, were grown by thermal evaporation (at a substrate temperature of $20^{\circ} \mathrm{C}$ and a pressure of $p<5 \times 10^{-9}$ mbar during deposition) on naturally oxidized $\mathrm{Si}(001)$ substrates covered with a 4-nm-thick $\mathrm{Cr}$ buffer layer and capped with $5 \mathrm{~nm} \mathrm{Cr}$. The ${ }^{57} \mathrm{Fe}$ isotopic enrichment is $95 \%$. The crystalline nature of the individual layers was confirmed with high-angle x-ray diffraction (XRD), and x-ray reflectometry was used to confirm the layered structure. In Fig. 1, we show typical low-angle XRD scans of our $\left[{ }^{57} \mathrm{Fe}(4 \mathrm{~nm}) / M(4 \mathrm{~nm})\right]_{15}$ multilayers. The observation of superlattice reflections of at least up to third order qualitatively indicates good multilayer quality on a mesoscopic scale and smooth interfaces with little atomic mixing between the layers. ${ }^{15}$ The Fe/Ag multilayer shows only the first-order superlattice reflection, which is due to a larger interface roughness, and not due to an enhanced interdiffusion, as our conversion electron Mössbauer spectra (CEMS) results demonstrate (see below). Note that the second-order superstructure peak is suppressed because the individual Fe and $M$ thicknesses are equal.

We have evaluated CEMS with respect to the degree of interface alloying and metastable phase formation at the interface. Typical room-temperature CEMS of the thinnest multilayers $\left[{ }^{57} \mathrm{Fe}(1.5 \mathrm{~nm}) / M(4.0 \mathrm{~nm})\right]_{15}$ are shown in Fig. 2. All of the spectra are Zeeman-split sextets typical of ferromagnetic bcc-Fe layers with a small degree of interdiffusion on the atomic scale, as revealed by a weak line broadening and the slightly non-Lorentzian line shape. We would like to emphasize that a central single line, typical of paramagnetic fcc-Fe, ${ }^{16}$ is absent in all of the spectra, including $\mathrm{Fe} / \mathrm{Cu}$ and $\mathrm{Fe} / \mathrm{Co}$. Therefore, local fcc arrangement does not 


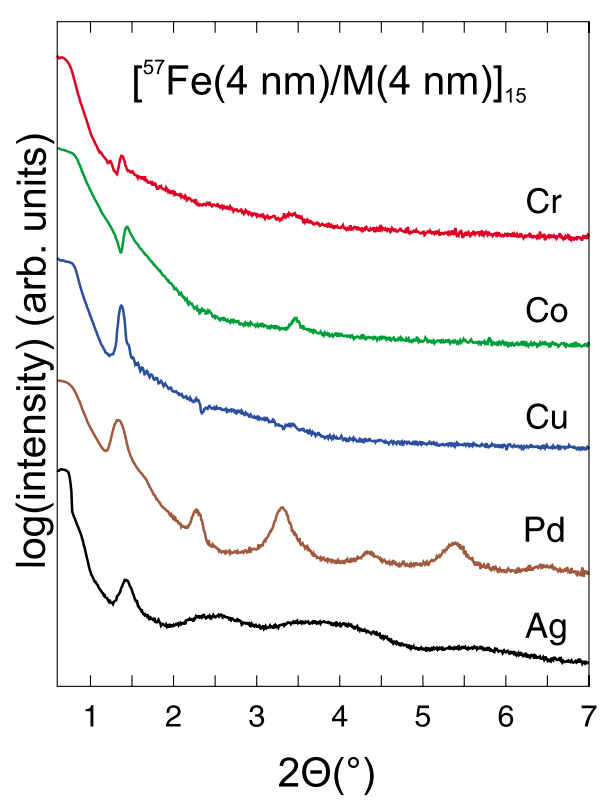

FIG. 1. (Color online) Typical small-angle x-ray diffraction scans of $\left[{ }^{57} \mathrm{Fe}(4 \mathrm{~nm}) / M(4 \mathrm{~nm})\right]_{15}$ multilayers with $M=\mathrm{Cr}$, Co, $\mathrm{Cu}, \mathrm{Pd}$, and $\mathrm{Ag}(\mathrm{Cu} K \alpha$ radiation $)$.

occur here. The spectra in Fig. 2 were least-squares fit with a distribution of hyperfine (hf) magnetic fields $\left[P\left(B_{\mathrm{hf}}\right)\right]$. The distributions $P\left(B_{\mathrm{hf}}\right)$ are shown in Fig. 2 (right-hand side). For all $\mathrm{Fe} / M$ multilayers, they exhibit a relatively sharp, dominant peak at $B_{\mathrm{hf}}=32 \mathrm{~T}(\mathrm{Fe} / \mathrm{Cr}), 34 \mathrm{~T}(\mathrm{Fe} / \mathrm{Co}), 31 \mathrm{~T}(\mathrm{Fe} / \mathrm{Cu})$, $33 \mathrm{~T}(\mathrm{Fe} / \mathrm{Pd})$, and $31.5 \mathrm{~T}(\mathrm{Fe} / \mathrm{Ag})$. These values are characteristic of the bcc structure (bulk bcc Fe: $33.0 \mathrm{~T}$ ). In addition, one may notice low field $P\left(B_{\mathrm{hf}}\right)$ tails for $\mathrm{Fe} / \mathrm{Cr}, \mathrm{Fe} / \mathrm{Cu}$, and $\mathrm{Fe} / \mathrm{Ag}$. These low field tails originate from the reduction in $B_{\mathrm{hf}}$ at interfacial ${ }^{57} \mathrm{Fe}$ atoms due to the presence of $\mathrm{Cr},{ }^{17,18}$ $\mathrm{Cu},{ }^{19}$ or $\mathrm{Ag}$ (Refs. 20 and 21) atoms in their local environment. We also emphasize that the $P\left(B_{\mathrm{hf}}\right)$ for our polycrystalline $\mathrm{Fe} / \mathrm{Cr}$ multilayers looks similar to the $P\left(B_{\mathrm{hf}}\right)$ for $\mathrm{Fe} /$ $\mathrm{Cr}(001)$ superlattices. ${ }^{18}$ The contribution of the low field tail to the total $P\left(B_{\mathrm{hf}}\right)$ can be used for an estimation of the interface sharpness. The ratio of the area below the tail and the area below the main peak of $P\left(B_{\mathrm{hf}}\right)$ represents the fraction of ${ }^{57} \mathrm{Fe}$ atoms in an ${ }^{57} \mathrm{Fe}$ layer interacting with $\mathrm{Cr}, \mathrm{Cu}$, and $\mathrm{Ag}$ atoms. This procedure provides estimates for the fraction of interfacial ${ }^{57} \mathrm{Fe}$ atoms in the $\left[{ }^{57} \mathrm{Fe}(1.5 \mathrm{~nm}) / M(4.0 \mathrm{~nm})\right]_{15}$ multilayers of $55 \%$ for $M=\mathrm{Cr}, 23 \%$ for $M=\mathrm{Cu}$, and $12 \%$ for $M=\mathrm{Ag}$. This is equivalent to an average ${ }^{57} \mathrm{Fe}$ layer thickness per interface, $t_{\text {int }}$ (affected by $M$ atoms), of about $0.4 \mathrm{~nm}$ (or $2 \mathrm{ML}$ ) for $\mathrm{Fe} / \mathrm{Cr}, 0.17 \mathrm{~nm}$ (or $0.8 \mathrm{ML}$ ) for $\mathrm{Fe} / \mathrm{Cu}$, and $0.1 \mathrm{~nm}$ (or $0.5 \mathrm{ML}$ ) for Fe/Ag. These values should be compared with the individual ${ }^{57} \mathrm{Fe}$ layer thickness of $t_{\mathrm{Fe}}=1.5 \mathrm{~nm}$ or 7.5 ML. [1 ML (monolayer) is equal to about $0.2 \mathrm{~nm}$, assuming ${ }^{57} \mathrm{Fe}(110)$ growth.] The small values of $t_{\text {int }}$ indicate that ${ }^{57} \mathrm{Fe}-M$ interdiffusion is very small and limited to the first interfacial $\mathrm{Fe}$ monolayer in $\mathrm{Fe} / \mathrm{Cu}$ and $\mathrm{Fe} / \mathrm{Ag}$ and to the first two interfacial $\mathrm{Fe}$ monolayers in $\mathrm{Fe} / \mathrm{Cr}$. As to the distributions $P\left(B_{\mathrm{hf}}\right)$ of the $\mathrm{Fe} / \mathrm{Co}$ and $\mathrm{Fe} / \mathrm{Pd}$ multilayers shown in Fig. 2, they exhibit a broadened main peak shifted slightly to higher hf fields and no low field tail. $P\left(B_{\mathrm{hf}}\right)$ ranges from 31 to $38 \mathrm{~T}$ for $\mathrm{Fe} / \mathrm{Co}$ and from 29 to $38 \mathrm{~T}$ for $\mathrm{Fe} / \mathrm{Pd}$. This

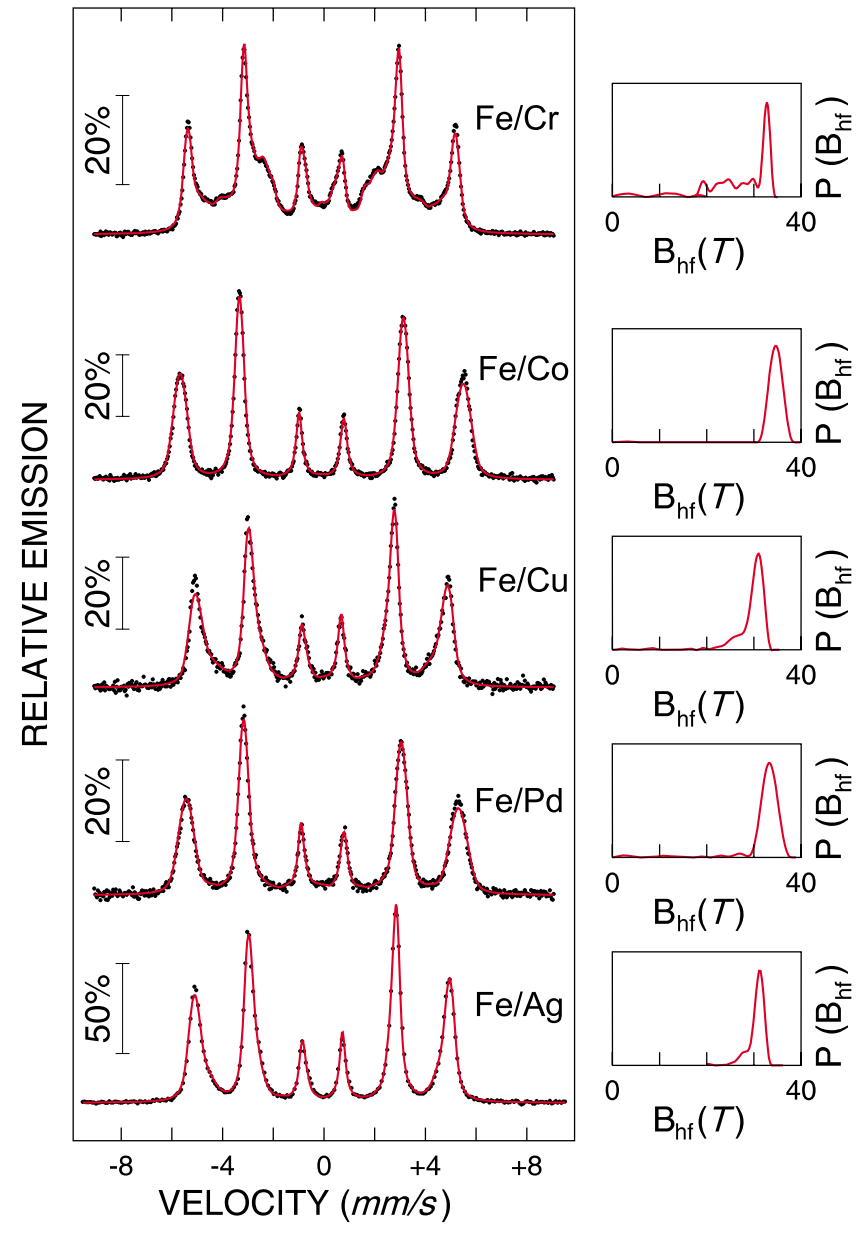

FIG. 2. (Color online) Typical ${ }^{57} \mathrm{Fe}$ CEMS of $\left[{ }^{57} \mathrm{Fe}(1.5 \mathrm{~nm}) / M(4 \mathrm{~nm})\right]_{15}$ multilayers with $M=\mathrm{Cr}, \mathrm{Co}, \mathrm{Cu}, \mathrm{Pd}$, and $\mathrm{Ag}$ taken at room temperature. Right-hand side: corresponding magnetic hyperfine field distributions $P\left(B_{\mathrm{hf}}\right)$.

broadening clearly indicates the presence of a distribution of ${ }^{57} \mathrm{Fe}$ sites in these multilayers. These ${ }^{57} \mathrm{Fe}$ sites may be attributed to a combination of several configurations: $:^{22,23} \alpha$-Fe $\left(B_{\mathrm{hf}}=33.0 \mathrm{~T}\right)$, bcc-Co $(31.2 \mathrm{~T}), \mathrm{Fe} / \mathrm{Co}$ interface region $(35.4$ $\mathrm{T}$, enhanced), and hcp-Co $(\sim 32 \mathrm{~T})$. Since the $P\left(B_{\mathrm{hf}}\right)$ range in Fig. 2 for $\mathrm{Fe} / \mathrm{Co}$ extends to large hf fields, we may estimate from the shape of $P\left(B_{\mathrm{hf}}\right)$ that the interdiffused $\mathrm{Fe} / \mathrm{Co}$ interface region (with $35.4 \mathrm{~T}$ ) contributes roughly $50 \%$ to $P\left(B_{\mathrm{hf}}\right)$. Thus, the amount of interdiffusion in Fe/Co appears to be similar to that in our $\mathrm{Fe} / \mathrm{Cr}$ multilayers. Similar conclusions can be drawn from $P\left(B_{\mathrm{hf}}\right)$ for our $\mathrm{Fe} / \mathrm{Pd}$ multilayers, since enlarged hf fields have also been reported for $\mathrm{Fe} / \mathrm{Pd}$ interfaces at room temperature. ${ }^{24}$ Summarizing, we may claim from the CEMS results that interfacial interdiffusion in our multilayers is strongest for $\mathrm{Fe} / \mathrm{Cr}, \mathrm{Fe} / \mathrm{Co}$, and $\mathrm{Fe} / \mathrm{Pd}$ $(\sim 2 \mathrm{ML} \mathrm{Fe}$ per interface) and little for $\mathrm{Fe} / \mathrm{Cu}$ and $\mathrm{Fe} / \mathrm{Ag}$ $(\sim 1$ ML Fe per interface). We point out that, in particular, the "soft" metal $M=P d$ exhibits a similar amount of interdiffusion as the "hard" metals Cr and Co. Thus, the degree of interdiffusion is not correlated to the phonon cutoff energy $E_{M}$ of metal $M$.

In order to investigate the crystallographic structure and grain size of our $\left[\mathrm{Fe}\left(t_{\mathrm{Fe}}\right) / M(4.0 \mathrm{~nm})\right]_{15}$ multilayers as a 
function of $t_{\mathrm{Fe}}$, we have performed extensive $\theta-2 \theta$ high-angle XRD measurements ${ }^{25}$ (not shown). These results may be summarized as follows: (i) Fe and $M$ layers were found to be polycrystalline. The Fe layers are bcc (in agreement with the CEMS results), and the $M$ layers are bcc (Cr), hcp (Co), or fcc $(\mathrm{Cu}, \mathrm{Pd}, \mathrm{Ag})$. (ii) With decreasing $t_{\mathrm{Fe}}$, the Fe layer lattice parameter was found to increase for $\mathrm{Fe} / \mathrm{Cr}, \mathrm{Fe} / \mathrm{Cu}$, and $\mathrm{Fe} /$ $\mathrm{Ag}$, and remained constant for $\mathrm{Fe} / \mathrm{Co}$. (iii) The crystallographic texture of the Fe layers was determined from the integrated intensity ratio of $\mathrm{Fe}(110)$ and $\mathrm{Fe}(211)$ reflections. The Fe layers always showed a (110) texture [with $\mathrm{Fe}(110)$ lattice planes parallel to the film plane]. For $M=\mathrm{Pd}$ and $\mathrm{Ag}$, the $\mathrm{Pd}(111)$ and $\operatorname{Ag}(111)$ reflections were surrounded by satellite peaks due to the multilayer periodicity, indicating a perfect $\mathrm{Fe}(110)$ growth parallel to $\mathrm{Pd}(111)$ and $\mathrm{Ag}(111)$ lattice planes [marked $\mathrm{Fe}(110)$ texture] independent of $t_{\mathrm{Fe}}$. Comparing $\mathrm{Fe}$ in $\mathrm{Fe} / \mathrm{Cr}, \mathrm{Fe} / \mathrm{Co}$, and $\mathrm{Fe} / \mathrm{Cu}$, generally, $\mathrm{Fe} / \mathrm{Cu}$ had a larger (110) texture than $\mathrm{Fe} / \mathrm{Cr}$, with $\mathrm{Fe} / \mathrm{Co}$ in between. Upon decreasing $t_{\mathrm{Fe}}$ from 8 to $4 \mathrm{~nm}$, the (110) texture decreased by $\sim 48 \%$ for $\mathrm{Fe} / \mathrm{Cu}$, by $\sim 49 \%$ for $\mathrm{Fe} / \mathrm{Co}$, and by $\sim 16 \%$ for Fe/Cr. (iv) The average grain size in the Fe layers was estimated from the width of the $\mathrm{Fe}(110)$ Bragg reflections by using the Scherrer formula. The $\theta-2 \theta$ geometry provides the grain dimension perpendicular to the film plane. At $t_{\mathrm{Fe}}=8 \mathrm{~nm}$, the $\mathrm{Fe}$ grain size was found to be $\sim 18 \mathrm{~nm}$ for $\mathrm{Fe} / \mathrm{Cr}, \sim 13 \mathrm{~nm}$ for $\mathrm{Fe} / \mathrm{Pd}, \sim 12 \mathrm{~nm}$ for $\mathrm{Fe} / \mathrm{Co}, \sim 8 \mathrm{~nm}$ for $\mathrm{Fe} / \mathrm{Cu}$, and $\sim 5 \mathrm{~nm}$ for Fe/Ag. With decreasing $t_{\mathrm{Fe}}$, we observed a monotonic decrease in the $\mathrm{Fe}$ grain size, e.g., to $\sim 16 \mathrm{~nm}(\mathrm{Fe} / \mathrm{Cr}), \sim 9 \mathrm{~nm}(\mathrm{Fe} / \mathrm{Pd}), \sim 6 \mathrm{~nm}(\mathrm{Fe} / \mathrm{Co})$, and $\sim 5 \mathrm{~nm}(\mathrm{Fe} / \mathrm{Cu})$, all at $t_{\mathrm{Fe}}=2 \mathrm{~nm}$. For $t_{\mathrm{Fe}}=4 \mathrm{~nm}$, the grain size in $\mathrm{Fe} / \mathrm{Ag}$ was $\sim 4 \mathrm{~nm}$. Summarizing all of the highangle XRD results, we can say that none of the quantities described in items (i)-(iv) above show a correlation with the phonon cutoff energy $E_{M}$ of the metal $M$, i.e., no systematic behavior in the crystal structure, lattice parameter, texture, and grain size for $\mathrm{Fe}$ in the multilayers could be found, which would follow the sequence $\mathrm{Cr}$, Co (both hard), $\mathrm{Cu}$ ("medium hard"), Pd (soft), and Ag (soft).

NRIXS measurements were performed at room temperature at beamline 3-ID of the Advanced Photon Source. The synchrotron-beam energy was scanned around the resonant energy of the ${ }^{57} \mathrm{Fe}$ nucleus $(14.413 \mathrm{keV})$ with an energy resolution of 1.3 or $2.2 \mathrm{meV}$. The monochromatic beam hits the sample surface at grazing incidence and the NRIXS data measure the phonon excitation probability, as described in Refs. 26-30. For each sample, the instrumental resolution function was determined by measuring the nuclear forward scattering intensity.

\section{RESULTS AND DISCUSSION}

Figure 3 displays typical NRIXS data measured on two $\left[{ }^{57} \mathrm{Fe}\left(t_{\mathrm{Fe}}\right) / \mathrm{Ag}(4 \mathrm{~nm})\right]_{15}$ multilayers with $t_{\mathrm{Fe}}=2$ and $8 \mathrm{~nm}$. By using the PHOENIX software, ${ }^{30}$ the spectra have been decomposed into single-phonon $[\propto g(E)]$ and multiphonon contributions. As an example, Fig. 4 shows representative $\mathrm{Fe}-$ projected $g(E)$ 's, which are typical of the multilayers and of a reference bulk bcc- ${ }^{57} \mathrm{Fe}$ foil. For $\left[{ }^{57} \mathrm{Fe}\left(t_{\mathrm{Fe}}\right) / \mathrm{Ag}(4 \mathrm{~nm})\right]_{15}$, three striking systematic modifications of $g(E)$ may be noted

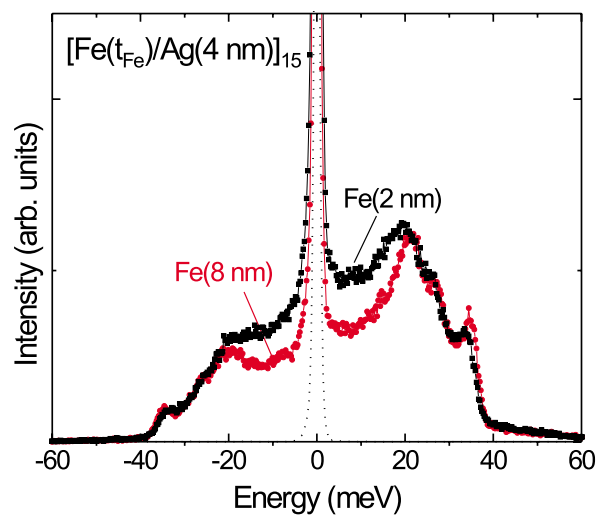

FIG. 3. (Color online) Typical NRIXS data measured at room temperature on $\left[{ }^{57} \mathrm{Fe}\left(t_{\mathrm{Fe}}\right) / \mathrm{Ag}(4 \mathrm{~nm})\right]_{15}$ multilayers with $t_{\mathrm{Fe}}=2$ and $8 \mathrm{~nm}$. Energy resolution: $1 \mathrm{meV}$. Dotted line: instrumental resolution function.

with decreasing $t_{\mathrm{Fe}}$ [Fig. 4(a)]: (i) a reduction in the longitudinal $^{31}$ (L) phonon peak height (at $36 \mathrm{meV}$ for bulk bcc-Fe); (ii) a shift to lower energy of the longitudinal peak position, combined with a weak broadening; and (iii) an enhancement of $g(E)$ at low phonon energies. There is an overall shift of $g(E)$ to lower energies with decreasing values of $t_{\mathrm{Fe}}$, implying a general softening of the lattice. Even for the thinnest $\mathrm{Fe}$ layers in our multilayers, there is no enhancement of $g(E)$ beyond the cutoff energy $E_{\mathrm{Fe}} \approx 39 \mathrm{meV}$ of bulk bcc-Fe. No drastic modification of the transverse $(T)$ phonon peaks near 23 and $27 \mathrm{meV}$ appears upon reducing the value of $t_{\mathrm{Fe}}$, except for a smearing and a shift to lower energy. Figure 4(b) displays $g(E)$ in $\left[{ }^{57} \mathrm{Fe}(2 \mathrm{~nm}) / M(4 \mathrm{~nm})\right]_{15}$ for $M=\mathrm{Cr}, \mathrm{Co}, \mathrm{Pd}$, and $\mathrm{Ag}$. While the L-phonon peaks of $\mathrm{Cr}$ and $\mathrm{Co}$ remain relatively high, they are strongly reduced and shifted to lower energies for $\mathrm{Pd}$ and $\mathrm{Ag}$. Relative to the case of $\mathrm{Cr}$ and $\mathrm{Co}$, an overall shift of $g(E)$ to lower $E$ (lattice softening) is found for Pd and $\mathrm{Ag}$. Figure 4(c) shows the VDOS of $\left[{ }^{57} \mathrm{Fe}(8 \mathrm{~nm}) / M(4 \mathrm{~nm})\right]_{15}$. In this case, $g(E)$ 's of Fe for different $M$ 's are nearly the same and resemble that of bulk bcc-Fe (except for small differences in the L-phonon peak heights). Similar features have been predicted by atomistic simulations of the VDOS of $\mathrm{Ag}$ nanograins and attributed to grain morphology and phonon localization. ${ }^{32}$

The most important result is shown in Fig. 5. In Figs. 5(a) and 5(b), the L-phonon $\mathrm{PH}$ near $36 \mathrm{meV}$ is displayed as a function of the VDOS mismatch between bulk Fe and bulk metals $M$ for our $\left[{ }^{57} \mathrm{Fe}\left(t_{\mathrm{Fe}}\right) / M(4 \mathrm{~nm})\right]_{15}$ multilayers, with $t_{\mathrm{Fe}}$ as a parameter. We define the VDOS mismatch either as the difference in phonon cutoff energies, $E_{\mathrm{Fe}}-E_{M}$, between bulk Fe and bulk metals ${ }^{33} M$ taken from Ref. 34 [Fig. 5(a)] or by the nonoverlapping area below $g(E)$ of bulk Fe [inset in Fig. 5(b)]. For comparison, we have also added earlier data from ${ }^{57} \mathrm{Fe}(2 \mathrm{~nm}) / \mathrm{Au}(4 \mathrm{~nm})$ multilayers. ${ }^{35}$ Note that in Figs. 5(a) and 5(b) , for the lowest $t_{\mathrm{Fe}}$ values, and starting from $\mathrm{Cr}$ with zero VDOS mismatch, the L-phonon PH first remains constant or changes only weakly with increasing VDOS mismatch up to $\mathrm{Co}$, and then exhibits a steplike decrease at $\mathrm{Cu}$ and Pd, followed by a modest change up to Ag. This steplike feature is strongest at the smallest thickness of $t_{\mathrm{Fe}}=1.5 \mathrm{~nm}$ 


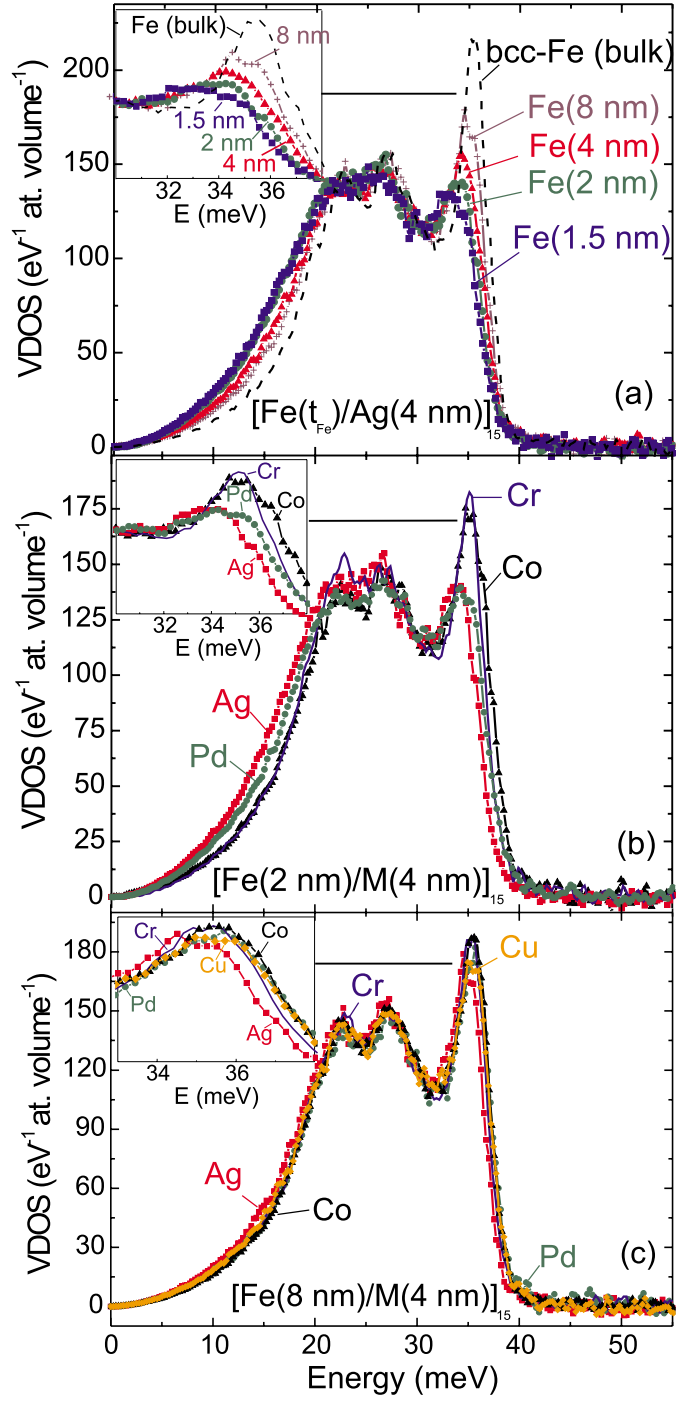

FIG. 4. (Color online) Fe-projected vibrational density of states $g(E)$ of $\left[{ }^{57} \mathrm{Fe}\left(t_{\mathrm{Fe}}\right) / M\left(t_{M}\right)\right]_{15}$ multilayers obtained from NRIXS at room temperature. (a) $M=\mathrm{Ag}, t_{\mathrm{Ag}}=4 \mathrm{~nm}$, and $t_{\mathrm{Fe}}=8 \mathrm{~nm}$ (crosses), $4 \mathrm{~nm}$ (triangles), $2 \mathrm{~nm}$ (circles), and $1.5 \mathrm{~nm}$ (squares). $g(E)$ of bulk bcc-Fe is also shown for reference (dotted). (b) $t_{\mathrm{Fe}}=2 \mathrm{~nm}, t_{M}$ $=4 \mathrm{~nm}$, and $M=\mathrm{Cr}$ (solid line), Co (triangles), $\mathrm{Pd}$ (circles), and $\mathrm{Ag}$ (squares). (c) $t_{\mathrm{Fe}}=8 \mathrm{~nm}, t_{M}=4 \mathrm{~nm}$, and $M=\mathrm{Cr}, \mathrm{Co}, \mathrm{Cu}, \mathrm{Pd}$, and $\mathrm{Ag}$ [same symbols as in (b) and $\mathrm{Cu}$ (diamonds)]. The insets show a zoom of the $36 \mathrm{meV}$ regions.

and becomes gradually less pronounced with increasing $t_{\mathrm{Fe}}$. Relative to the $\mathrm{Fe} / \mathrm{Cr}$ and $\mathrm{Fe} / \mathrm{Co} \mathrm{PHs}$, the suppression of the peak for $\mathrm{Fe} / \mathrm{Pd}$ and $\mathrm{Fe} / \mathrm{Ag}$ amounts to $\sim 24 \%$ at $t_{\mathrm{Fe}}$ $=1.5 \mathrm{~nm}$. The steplike feature observed in Figs. 5(a) and 5 (b) is a consequence of the fact that, due to the large VDOS mismatch, high-energy modes of $\mathrm{Fe}$ are not allowed to propagate in the $\mathrm{Cu}, \mathrm{Pd}, \mathrm{Ag}$, and $\mathrm{Au}$ layers and remain confined in the $\mathrm{Fe}$ layers, which constitute quasi-twodimensional systems with a large interface to volume ratio. These vibrational waves of short wavelength in the Fe layers should be strongly overdamped in the regions of $\mathrm{Fe} / M$ interfaces (with $M=\mathrm{Cu}, \mathrm{Pd}, \mathrm{Ag}$, and $\mathrm{Au}$ ), and much less so in the center of the Fe films, and their vibrational amplitude should decay over very short distances while penetrating into
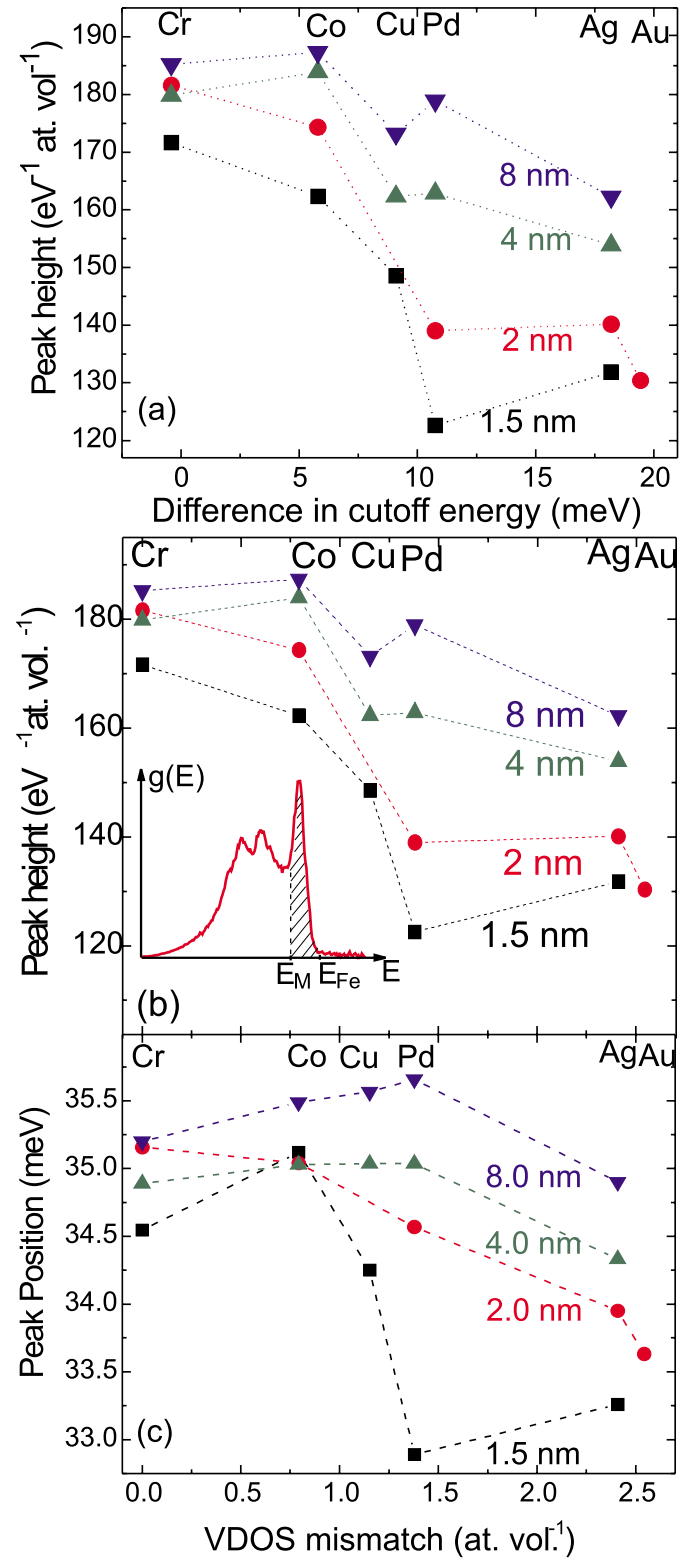

FIG. 5. (Color online) [(a) and (b)] Longitudinal phonon peak height and (c) peak position versus (a) $E_{\mathrm{Fe}}-E_{M}$ and versus [(b) and (c)] VDOS mismatch of metal $M(\mathrm{Au}, \mathrm{Ag}, \mathrm{Pd}, \mathrm{Cu}, \mathrm{Co}$, and $\mathrm{Cr}$ ) with respect to $\mathrm{Fe}$ for $\left[\mathrm{Fe}\left(t_{\mathrm{Fe}}\right) / M(4 \mathrm{~nm})\right]_{15}$ multilayers with $t_{\mathrm{Fe}}=8,4,2$, and $1.5 \mathrm{~nm}$. Inset in (b): the VDOS mismatch is defined by the dashed area below $g(E)$ of bulk bcc-Fe. $\left(E_{\mathrm{Fe}}, E_{M}=\right.$ phonon cutoff energy of $\mathrm{Fe}$ and metal $M$, respectively).

the soft metal layers. In the case of $\mathrm{Fe} / \mathrm{Cr}$ and $\mathrm{Fe} / \mathrm{Co}$, the phonons are allowed to propagate through the 82.5-nm-thick multilayer as a whole and, thus, exhibit a nearly bulk behavior.

The effect of confinement is also clearly revealed in Fig. 5(c), where a steplike change can be observed by plotting the measured longitudinal phonon peak position vs VDOS mismatch. Relative to bulk Fe, in the thinnest Fe layer $(1.5 \mathrm{~nm})$, the suppression of the longitudinal phonons by confinement results in a shift of $\sim 8 \%$ to lower energies for the soft metal $\mathrm{Ag}$, but only in a shift of $\sim 2 \%$ for the hard metals Co and $\mathrm{Cr}$. The presence of a shift qualitatively agrees with the pre- 
dictions in Ref. 14 of a shift to lower energies of the highenergy edge in ultrathin $\mathrm{Fe} / \mathrm{Au}$ multilayers.

We present a qualitative explanation for our findings [Figs. 5(a) and 5(b)] in terms of interface effects. The boundary condition at the $\mathrm{Fe} / M$ interface will affect the phonon dispersion relation and the elastic constants near the interface, which is known to result in localized low-energy phonon modes. ${ }^{11-13}$ Correspondingly, we observe a systematic increase in $g(E)$ at low energies $(E \leq \sim 20 \mathrm{meV})$ combined, however, with a systematic reduction in the $36 \mathrm{meV}$ peak height, depending on $M$ and $t_{\mathrm{Fe}}$ [Figs. 5(a) and 5(b)]. Therefore, it is reasonable to assume that lower-energy phonons in the $M$ layer ( $\mathrm{Pd}, \mathrm{Ag}$, and $\mathrm{Au}$ ) couple to those high-energy modes in the Fe layer that do not exist in the heavier $M$ layer (i.e., for $E_{M} \leq E \leq E_{\mathrm{Fe}}$ ). Thus, $\mathrm{Fe}$ atoms near the $M$ layer are constrained to movements at lower frequencies; in the extreme case, they are clamped to the interfacial heavy $M$ atoms instead of vibrating with high frequency. Hence, an $\mathrm{Fe}$ atom near the interface will have a reduced vibrational excitation probability for these high energies, $E_{M} \leq E \leq E_{\mathrm{Fe}}$. Therefore, the steplike behavior observed in Figs. 5(a) and 5(b) may be related to the availability of high-frequency vibrational states at the interface for the lighter $M$ layers $(\mathrm{Cr}$ and $\mathrm{Co}$ ), but not for the heavier layers ( $\mathrm{Pd}, \mathrm{Ag}$, and $\mathrm{Au}$ ). This can be interpreted as a confinement of the high-energy $\mathrm{Fe}$ phonons (within $E_{M} \leq E \leq E_{\mathrm{Fe}}$ ) if the heavier $M$ atoms do not move at all at these high frequencies. If this is the case, the interfacial $\mathrm{Fe}$ atoms (and probably their $\mathrm{Fe}$ neighbors within a small thickness range) will not move either at those high frequencies due to the Fe- $M$ coupling and the VDOS at 36 $\mathrm{meV}$ will be reduced. This is what we observed in Figs. 5(a) and 5(b). This argument must work for high-energy $\mathrm{L}$ and $T$ phonons of $\mathrm{Fe}$, and the confinement mechanism should be nonspecific to the phonon polarization. The extreme case of the "clamped-interface" boundary condition is reminiscent of the clamped-surface boundary condition for acoustic phonons ${ }^{36}$ in quantum wires, which leads to acoustic phonon confinement effects in the low-energy dispersion relations.

As can be noticed in Fig. 5, the steplike behavior due to confinement becomes more pronounced with decreasing $t_{\mathrm{Fe}}$ values, i.e., with increasing interface-to-volume ratio. We may estimate the effective interfacial Fe thickness, $t_{\text {int }}$, for which the phonons are affected by the boundary condition, using geometrical considerations. Previously, for the case of $\mathrm{Fe} / \mathrm{Cr}(001)$ superlattices, ${ }^{37}$ we demonstrated by NRIXS that boundary effects are localized and disappear in the Fe layer at a distance of $4 \mathrm{ML}(0.56 \mathrm{~nm})$ away from the $\mathrm{Fe} / \mathrm{Cr}$ interface, where a $g(E)$ value nearly that of bulk $\mathrm{Fe}$ is observed. Based on this result, we may assume that a modification of the $36 \mathrm{meV}$ peak occurs within $t_{\text {int }} \leq \sim 3 \mathrm{ML}(\sim 0.42 \mathrm{~nm})$, while the rest of the Fe layer shows "bulk" properties. By using this model for $t_{\mathrm{Fe}}=1.5 \mathrm{~nm}$, and by normalizing the $\mathrm{PH}$ to that of the 8-nm-thick Fe film in the present multilayers, we would expect relative $36 \mathrm{meV} \mathrm{PHs}$ of $\sim 49 \%$, 67\%, $\sim 84 \%$, and $\sim 92 \%$ for $t_{\mathrm{int}}=3,2,1$, and $0.5 \mathrm{ML}$, respectively. From Figs. 5(a) and 5(b), the corresponding measured normalized PHs at $t_{\mathrm{Fe}}=1.5 \mathrm{~nm}$ are $69 \%$ for $\mathrm{Fe} / \mathrm{Pd}, 82 \%$ for $\mathrm{Fe} / \mathrm{Ag}, 86 \%$ for $\mathrm{Fe} / \mathrm{Co}$ and $\mathrm{Fe} / \mathrm{Cu}$, and $93 \%$ for $\mathrm{Fe} / \mathrm{Cr}$. A comparison of the calculated and measured normalized PHs indicates $t_{\text {int }}$ values of $\sim 2 \mathrm{ML}$ for $\mathrm{Fe} / \mathrm{Pd}, \sim 1 \mathrm{ML}$ for $\mathrm{Fe} /$
$\mathrm{Ag}, \mathrm{Fe} / \mathrm{Cu}$, and $\mathrm{Fe} / \mathrm{Co}$, and $\sim 0.5 \mathrm{ML}$ for $\mathrm{Fe} / \mathrm{Cr}$. These values provide evidence that boundary effects in the $\mathrm{Fe}$ layers are short range and only extend over a few monolayers.

Recently, first-principles calculations ${ }^{38}$ and experimental results ${ }^{39,40}$ obtained by layer-resolved NRIXS on single-layer $\mathrm{Fe}(110)$ ultrathin films in ultrahigh vacuum revealed that the $\mathrm{Fe}$ atoms of the free surface layer vibrate with frequencies significantly lower than those in the bulk and, thus, are responsible for the reduction in the phonon peak at $36 \mathrm{meV}$ and the enhancement of $g(E)$ at low energies. Our present work on Fe films interleaved with $M$ metals demonstrates that this reduction at $36 \mathrm{meV}$ and low- $E$ enhancement strongly depend on the boundary conditions imposed by the $\mathrm{Fe} / M$ interfaces.

Finally, we address the question of whether the VDOS obtained from NRIXS measurements at grazing x-ray incidence could be an in-plane projected VDOS that possibly differs from the out-of-plane projected VDOS that one might measure at perpendicular incidence. Such a difference could possibly arise as a result of the (per se) anisotropic multilayer structure. In fact, the single-phonon nuclear inelastic absorption probability $W_{1}(E)$ depends on $\left|\mathbf{s} \cdot \mathbf{e}_{j}(\mathbf{q})\right|^{2}$, where $\mathbf{e}_{j}(\mathbf{q})$ is the polarization vector of a phonon with wave vector $\mathbf{q}$, and $\mathbf{s}=\mathbf{k} /|\mathbf{k}|$ is the photon momentum direction. ${ }^{41}$ Therefore, $W_{1}(E)$ for a particular phonon energy $E$ scales with $\cos ^{2}\left(\theta_{j}\right)$ (with $\theta_{j}$ being the angle between the phonon polarization vector $\mathbf{e}_{j}$ and the photon direction $\mathbf{s}$ ), and contributions of various phonon modes $j$ are weighted by $\cos ^{2}\left(\theta_{j}\right)$. In this way, for our geometry of grazing incidence, one obtains the VDOS of ${ }^{57} \mathrm{Fe}$ atoms in the multilayers weighted along the in-plane direction. In this sense, our measured VDOS could be partial-in-plane and, since the multilayer structure is anisotropic, it might differ from the VDOS measured with the photon momentum direction perpendicular to the film plane. The latter case is presently not well accessible due to the experimental geometry. However, since the boundary effect on the VDOS in the Fe layers is short range and limited to a very few monolayers near the interface only, ${ }^{37,39,40}$ such anisotropic effects in the VDOS are expected to be observable for Fe film thicknesses in the monolayer range only.

\section{CONCLUSIONS}

In conclusion, we present evidence of high-energy phonon confinement and interface localization in nanoscale metallic $\mathrm{Fe} / M$ multilayers. The suppression and energy shift of the longitudinal phonon peak in $g(E)$ of the Fe layers near 36 $\mathrm{meV}$ depend on the energy mismatch between $g(E)$ of Fe and of the metal $M$ and become more pronounced with increasing interface-to-volume ratio as the Fe layer thickness decreases. High-energy vibrational modes of interfacial $\mathrm{Fe}$ atoms that find no high-energy counterpart in the heavy $M$ layer couple to lower-energy phonons in the $M$ layer ( $M$ $=\mathrm{Pd}, \mathrm{Ag}$, and $\mathrm{Au}$ ), thereby reducing the $36 \mathrm{meV}$ longitudinal VDOS peak of Fe. These findings should represent general properties of metallic multilayers and should have a strong impact on their thermodynamic properties and thermal conductivity. 


\section{ACKNOWLEDGMENTS}

Discussions with R. Meyer (Duisburg), A. Kara, and P. Schelling (UCF) are appreciated. The work was supported by
DFG (Grant Nos. GRK 277 and SFB 491), by NSF (Grant No. CAREER DMR-0448491), and by U.S. DOE (Grant No. DE-AC02-06CH11357). *roldan@physics.ucf.edu

${ }^{1}$ B. Jusserand and M. Cardona, in Light Scattering in Solids V, Topics in Applied Physics, edited by M. Cardona and G. Güntherodt (Springer, Berlin, 1989), p. 49.

${ }^{2}$ C. Colvard, R. Merlin, M. V. Klein, and A. C. Gossard, Phys. Rev. Lett. 45, 298 (1980).

${ }^{3}$ A. K. Sood, J. Menendez, M. Cardona, and K. Ploog, Phys. Rev. Lett. 54, 2111 (1985).

${ }^{4}$ A. K. Sood, J. Menendez, M. Cardona, and K. Ploog, Phys. Rev. Lett. 54, 2115 (1985).

${ }^{5}$ G. P. Srivastava, The Physics of Phonons (Adam Hilger, Bristol, 1990), Chap. 8, p. 253.

${ }^{6}$ D. Vashaee and A. Shakouri, Phys. Rev. Lett. 92, 106103 (2004).

${ }^{7}$ T. Gorishnyy, C. K. Ullal, M. Maldovan, G. Fytas, and E. L. Thomas, Phys. Rev. Lett. 94, 115501 (2005).

${ }^{8}$ G. Bergmann, Phys. Rev. B 75, 195427 (2007).

${ }^{9}$ L. Wang and B. Li, Phys. Rev. Lett. 99, 177208 (2007).

${ }^{10}$ M. Grimsditch, J. E. Mattson, C. H. Sowers, S. D. Bader, and M. J. Peters, Phys. Rev. Lett. 77, 2025 (1996).

${ }^{11}$ P. Baumgart, B. Hillebrands, R. Mock, G. Güntherodt, A. Boufelfel, and C. M. Falco, Phys. Rev. B 34, 9004 (1986).

${ }^{12}$ J. A. Bell, W. R. Bennett, R. Zanoni, G. I. Stegeman, C. M. Falco, and F. Nizzoli, Phys. Rev. B 35, 4127 (1987).

${ }^{13}$ J. R. Dutcher, S. Lee, J. Kim, G. I. Stegeman, and C. M. Falco, Phys. Rev. Lett. 65, 1231 (1990).

${ }^{14}$ M. Sternik, K. Parlinski, and J. Korecki, Phys. Rev. B 74, 195405 (2006).

${ }^{15}$ E. E. Fullerton, D. M. Kelly, J. Guimpel, I. K. Schuller, and Y. Bruynseraede, Phys. Rev. Lett. 68, 859 (1992).

${ }^{16}$ W. Keune, R. Halbauer, U. Gonser, J. Lauer, and D. L. Williamson, J. Appl. Phys. 48, 2976 (1977).

${ }^{17}$ F. Klinkhammer, Ch. Sauer, E. Yu. Tsymbal, S. Handschuh, Q. Leng, and W. Zinn, J. Magn. Magn. Mater. 161, 49 (1996).

${ }^{18}$ V. M. Uzdin, W. Keune, H. Schrör, and M. Walterfang, Phys. Rev. B 63, 104407 (2001).

${ }^{19}$ P. J. Schurer, B. Scully, M. Kowalewski, and B. Heinrich, J. Magn. Magn. Mater. 224, 65 (2001).

${ }^{20}$ P. J. Schurer, Z. Celinski, and B. Heinrich, Phys. Rev. B 48, 2577 (1993).

${ }^{21}$ P. J. Schurer, Z. Celinski, and B. Heinrich, Phys. Rev. B 51, 2506 (1995).

${ }^{22}$ J. Dekoster, H. Bemelmans, S. Degroote, J. De Wachter, E. Jedryka, R. Moons, A. Vantomme, and G. Langouche, Hyperfine Interact. 95, 191 (1995).

${ }^{23}$ B. Kalska, P. Blomquist, L. Häggström, and R. Wäppling, J. Magn. Magn. Mater. 226-230, 1773 (2001).
${ }^{24}$ G. Kisters, Ch. Sauer, E. Tsymbal, and W. Zinn, Hyperfine Interact. 92, 1285 (1994).

${ }^{25}$ U. von Hörsten, E. Schuster, and W. Keune (unpublished).

${ }^{26}$ M. Seto, Y. Yoda, S. Kikuta, X. W. Zhang, and M. Ando, Phys. Rev. Lett. 74, 3828 (1995).

${ }^{27}$ W. Sturhahn, T. S. Toellner, E. E. Alp, X. Zhang, M. Ando, Y. Yoda, S. Kikuta, M. Seto, C. W. Kimball, and B. Dabrowski, Phys. Rev. Lett. 74, 3832 (1995).

${ }^{28}$ A. I. Chumakov, R. Rüffer, H. Grünsteudel, H. F. Grünsteudel, G. Grubel, J. Metge, and H. A. Goodwin, Europhys. Lett. 30, 427 (1995).

${ }^{29}$ A. I. Chumakov and W. Sturhahn, Hyperfine Interact. 123-124, 781 (1999)

${ }^{30}$ W. Sturhahn, Hyperfine Interact. 125, 149 (2000).

${ }^{31}$ In the VDOS of bulk Fe, a tail of the transverse $(T)$ phonons exists up to the cutoff energy $E_{\mathrm{Fe}}$, even though at only $\sim 15 \%$ of the longitudinal (L) phonons for $E>33 \mathrm{meV}$. Since the contribution of $T$ phonons is small, we label the VDOS peak at 36 $\mathrm{meV}$ as a longitudinal phonon peak.

${ }^{32}$ G. A. Narvaez, J. Kim, and J. W. Wilkins, Phys. Rev. B 72, 155411 (2005).

${ }^{33}$ We have used $E_{M}=9.5 \mathrm{THz}(39.3 \mathrm{meV}, \mathrm{Cr}), 8.0 \mathrm{THz}(33.1 \mathrm{meV}$, Co), 7.2 THz (29.8 meV, Cu), $6.8 \mathrm{THz}(28.1 \mathrm{meV}, \mathrm{Pd}), 5.0 \mathrm{THz}$ (20.7 meV, Ag), 4.7 THz (19.44 meV, Au), and $E_{\mathrm{Fe}}=9.4 \mathrm{THz}$ (39.3 meV) from Ref. 34.

${ }^{34}$ P. H. Dederichs, H. Schober, and D. J. Sellmyer, in Metals: Phonon States, Electron States and Fermi Surfaces, LandoltBörnstein, New Series, Group III, Vol. 13, edited by K.-H. Hellwege and J. L. Olsen (Springer, Heidelberg, 1981).

${ }^{35}$ E. E. Alp, W. Sturhahn, and T. S. Toellner, Hyperfine Interact. 135, 295 (2001).

${ }^{36}$ S. G. Yu, K. W. Kim, M. A. Stroscio, and G. J. Iafrate, Phys. Rev. B 51, 4695 (1995).

${ }^{37}$ T. Ruckert, W. Keune, W. Sturhahn, M. Y. Hu, J. P. Sutter, T. S. Toellner, and E. E. Alp, Hyperfine Interact. 126, 363 (2000).

${ }^{38}$ J. Lazewski, J. Korecki, and K. Parlinski, Phys. Rev. B 75, 054303 (2007).

${ }^{39}$ T. Slezak, J. Lazewski, S. Stankov, K. Parlinski, R. Reitinger, M. Rennhofer, R. Rüffer, B. Sepiol, M. Slezak, N. Spiridis, M. Zajac, A. I. Chumakov, and J. Korecki, Phys. Rev. Lett. 99, 066103 (2007).

${ }^{40}$ S. Stankov, R. Röhlsberger, T. Slezak, M. Sladecek, B. Sepiol, G. Vogl, A. I. Chumakov, R. Rüffer, N. Spiridis, J. Lazewski, K. Parlinski, and J. Korecki, Phys. Rev. Lett. 99, 185501 (2007).

${ }^{41}$ V. G. Kohn, A. I. Chumakov, and R. Rüffer, Phys. Rev. B 58, 8437 (1998). 